\title{
Analysis of Social-Economic Factors on Population Change in Heilongjiang Province
}

\author{
Ying Zhou $^{1}$, Haiyan $\mathrm{Gu}^{1}$ \\ ${ }^{1}$ Northeast Forestry University, Harbin, China \\ Correspondence: Haiyan Gu, Northeast Forestry University, Harbin, China
}

Received: October 2, $2021 \quad$ Accepted: November 15, $2021 \quad$ Online Published: November 22, 2021

doi:10.5539/jmr.v13n6p52

URL: https://doi.org/10.5539/jmr.v13n6p52

\begin{abstract}
The population is a constituent element of human society and is one of the indicators of a country's comprehensive strength. The quantity and quality of population directly determine the level of development of a country or region. Too small a population makes a country or region lack the motivation to develop, and too large a population strains local resources. Therefore, the state introduces relevant policies to regulate the population quantity in China. The analysis of the factors influencing the change in population size helps assess the current state of development and is essential for planning its future prosperity. This paper analyzes the impact of social-economics factors on population size change in Heilongjiang province since China's reform and opening up using double-logarithmic model (DLM) estimated by Elastic Net estimation (ENE). Meanwhile, this paper provides some policy recommendations to promote the growth of population size in Heilongjiang Province.
\end{abstract}

Keywords: social-economic factors, DLM, ENE, population

\section{Introduction}

According to the China Economic Trends Report, China's economy has transformed from high-speed development to high-quality development. But China's growth already has suffered from a large income gap between urban and rural people and the sustainable development of natural resources. A large population and abundant natural material resources have become less useful for China's economic growth. The population is an important indicator to measure the level of development of a region. Scholars' research on the topic of the population helps enhance the overall strength and improve the living standard of people in a region. The impact of the demographic transition on China's economic growth is analyzed from both quantitative and qualitative perspectives through theoretical and empirical evidence. The results show a qualitative demographic dividend effect replacing the quantitative demographic dividend effect in China's demographic transition and that there are regional differences in the effects of the quantitative and qualitative demographic shifts on China's economic growth (Zhou, 2018). Fertility is the primary factor influencing population development. New China's population fertility policy has gone through three different phases: natural fertility, birth control, and family planning. The relationship between fertility policy and China's population size and economy has been studied since the founding of New China (Zhu, 2013). Based on the Solow growth model and the endogenous growth model, it is concluded that the full liberalization of China's two-child population fertility policy is conducive to increasing the proportion of the working-age population and the future standard of living of the Chinese population (Chi, 2015). An analyzes of the characteristics of population size and density growth in Beijing and Tianjin in China, as well as in some cities in Hebei province, reveals that natural conditions and economic factors are responsible for the differences in population in the region. The population growth in areas with high per capita GDP growth and good tertiary industry development is higher (Li \& Chen, 2009). Economic-type factors, education-type factors, and natural and mechanical population growth are the three major influencing factors of rapid population growth in Beijing, based on the method of data mining and correlation test and Granger causality test (Shen \& Wu, 2013). With economic reform in China, population migration growth became the main cause of urban population growth (Wang \& Huang, 2014). The lower the transportation resistance, the higher the expected income ratio, the lower the residential price growth, and the higher the number of people moving into the area (Li, Tian \& Huang, 2021). Economic factors, social development, and financial level are important reasons for the population growth shift in the Yangtze River Delta of China (Yan, Sun, Wang \& Xu, 2020). Geographic information system spatial analysis method was used to analyze the factors influencing the population distribution in terms of topographic relief, GDP per capita and total foreign investment in Vietnam. The results showed that the natural geographical factors determined the basic situation of population distribution, GDP per capita, and total foreign investment were the fundamental drivers of population migration, and the relaxed fertility policy contributed to the rapid 
population growth in border areas in Vietnam (Yin, Li, Feng, You \& Xiao, 2021). After the early 19th century, infectious diseases have not been a menace to American society and the white population was increasing (Ding, 2021). Economic, administrative, and policy factors influence urban population growth in China, and the role of economic factors in urban population growth is becoming more and more significant in terms of development trends, while the effectiveness of policy and organizational factors is decreasing (Zhong, 2020). Economic factors are the main cause of urban population growth, infrastructure development such as education and transportation are secondary factors affecting urban population growth, and social factors such as urban-rural disparity have almost no effect on urban population growth in China (Zheng, 2007). Population size structure and maximum size of managed sportfish populations are dictated by abiotic, biotic, ecosystem, and anthropogenic influences (Markov, 1997). Climatic factors have less influence on changes in population size. The effect of natural amenities on population growth and changes in housing density within the county varies by age group (Kline, Montgomery \& Lee, 2016). Data from rural population sample surveys in Jiangsu, Anhui, Henan, Hunan, Sichuan, and Jilin provinces in China show that the labor force is mainly engaged in non-agricultural production when the rural population migrates to urban areas and the later the age of birth of people, the higher the probability of migration from rural to urban areas (Wang, 2015). The study found that the adaptability of the immigrant individuals to the region they moved into has nothing to do with the length of education, and income of the immigrant individuals but is more related to the type of work the immigrant individuals are engaged in (Wang \& Zhao, 2020). Using population mobility theory, population urbanization theory and scale theory as the basis, a multi-scale urbanization analysis framework is proposed based on population mobility, and policy recommendations are given to promote the development of new urbanization in the future. Such as narrowing the development gap between regions is conducive to reducing the inter-provincial migration of population while strengthening education and training for farmers and improving their endogenous power to settle down permanently in cities (Yang, 2016).

Persistence models have explored the effects of stochastic demographic and environmental changes on extinction. However, when a directional change in the environment, such as global warming, population persistence models must consider whether the population can adapt to such changes. Simulation results show that demographic factors (e.g., natural growth rate) and genetic factors have different effects on population persistence (Willi \& Hoffmann, 2009). Changing population age structures affect the level of economic development of a region. On average, an increase in the proportion of the working-age population by 1 percentage point would lead to an increase of about 1.6 percentage points in per capita GDP (Cruz \& Ahmed, 2018). Topography, climate, mineral, history and culture, economy, and transportation have affected the population distribution of Sichuan Province. Altitude and natural population growth are not conducive to population build-up. Higher GDP per capita and total retail sales of consumer goods help population migration (Guo, 2014). The causes of low fertility levels in the Northeast have been analyzed regarding population policy, social-economic, and women of childbearing age. (Hou, 2010). Economic development, the scale of college enrollment, and the geographical advantage are the driving mechanisms of population migration (Pang, 2007). In general, regional population is influenced by natural factors and mechanical changes in population ( $\mathrm{Li} \& \mathrm{Chen}, 2009$ ). Both natural and social-economic factors can impact population growth, so a higher level of economic development, better medical conditions, and more developed communication capabilities can contribute to regional population growth in China (Wang, Feng \& Yang 2015).

Heilongjiang Province is located in the northeastern part of China. It is bordered by Inner Mongolia to the west, Jilin to the north, and Russia to the east and north. It is an essential link between China and the Asian and Pacific regions, Russia and the European continent, and an important open city on the Chinese border. Heilongjiang has a land area of 473,000 square kilometers, which is $4.9 \%$ of the total land area of China. It is endowed with abundant material resources. It has a resident population of over 37 million and currently has 12 prefecture-level cities, 21 county-level cities, and dozens of municipal districts and counties. It has a continental monsoon climate with abundant precipitation in the summer and dry winters with little rain. Most previous studies have analyzed the impact of population migration on economic development in Heilongjiang Province while ignoring the effect of social-economic factors on population migration( $\mathrm{Du}, 2013 ; \mathrm{Li}, 2015$; Zhang, 2019). This paper developed a DLM based on ENE to study the impact of social-economic factors on population change in Heilongiiang province since the reform and opening up.

This paper contributions can be summarized as follows:

- This paper proposes a double-logarithmic model based on Elastic Net estimation and use this model to analyze the problem practically. The findings show that the fitted results of the model can describe the population pattern of Heilongjiang province.

- This paper complements the study of demographic issues in Heilongjiang Province. At the same time, the paper provide some recommendations for the government to promote the development of the population.

- This paper studies the population problem of Heilongjiang Province from the perspective of social-economic factors in 
an innovative way, which is a new way to study the population problem of Heilongjiang Province.

The paper is organized as follows. Section 2 describes the data and the model. Section 3 develops the model. Section 4 discusses the model. Section 5 provides conclusions.

\section{Materials and Methods}

\subsection{Selection of Social-Economic Factors Affecting Changes in Population Size}

The total population (10000 persons) of Heilongjiang Province from 1978 to 2019 was selected as the response variable. Based on previous studies (Pang, 2007; Wang et al., 2014), Three social-economic factors that may affect changes in population size were chosen as predictor variables. Among these factors, the number of new students enrollment by regular institutions of higher education (10000 persons), number of hospital beds (units), and length of railways in operation $(\mathrm{km})$ show the level of education development, traffic accessibility, and health security .

\subsection{Data and Pre-Processing}

In this paper, data from 1978 to 2019 are used. The data were obtained from the Heilongjiang Provincial Statistical Yearbook. The data from 1978 to 2017 were used to build a model to analyze the impact of social-economic factors on population change in Heilongjiang Province. This paper uses the data from 2018 and 2019 to test the accuracy of the model. At the same time, in order to eliminate the influence of different units of data on the model results, the above data were logarithmized to create the model.

\subsection{Elastic Net Estimation (ENE)}

Zou and Hastie proposed the (ENE) in 2005, and the ENE method is defined as follows.

And

$$
\hat{\beta}(E N)=\arg \min \sum_{\mathrm{i}=1}^{n}\left(y_{i}-\beta_{0}-\sum_{j=1}^{p} \beta_{j} x_{i j}\right)+\lambda\left[(1-\alpha)\|\beta\|_{2}^{2} / 2+\alpha\|\beta\|_{1}\right]
$$

$$
\|\beta\|_{1}=\sum_{j=1}^{p}\left|\beta_{j}\right| \quad\|\beta\|_{2}=\sqrt{\sum_{j=1}^{p} \beta_{j}^{2}}
$$

$y_{\mathrm{i}}$ is the $i$ th sample data of the response variable, $x_{i j}$ is the $i$ th sample data of the $j$ th predictor variable, $\beta_{0}, \beta_{j}$ are the regression coefficients, $\lambda$ is the penalty parameter that controls the degree of penalty, and $\alpha$ controls the weight of the combination of the two penalty terms.

When $\alpha=0$ the ENE becomes a ridge estimation(RE), and when $\alpha=1$ the ENE becomes a lasso estimation(LE). The penalty term of ENE is a linear combination of the penalty term of RE and LE. Therefore, ENE has the advantage of RE and LE. The ENE not only solves the problem of co-linearity between independent variables but also accomplishes the purpose of filtering variables.

\section{Model}

This paper create the DLM based on the number of new students enrollment by regular institutions of higher education, number of hospital beds, and length of railways in operation on the total population of Heilongjiang Province.

$$
\ln Y=\beta_{0}+\beta_{1} \ln X_{1}+\beta_{2} \ln X_{2}+\beta_{3} \ln X_{3}+\varepsilon
$$

$X_{1}, X_{2}, X_{3}, Y$ denote the number of new students enrollment by regular institutions of higher education, number of hospital beds, length of railways in operation and total population of Heilongjiang Province. $\ln \left(X_{1}\right), \ln \left(X_{2}\right) \ln \left(X_{3}\right)$ $\ln (Y)$ mean the logarithm of the number of new students enrollment by regular institutions of higher education , number of hospital beds, length of railways in operation and total population of Heilongjiang Province. $\varepsilon$ represents the error term, which indicates the effect of factors other than $X_{1}, X_{2}, X_{3}$ on the response variable as well as the error in data collection, and the assumed error of the model. $\beta_{i}, i=0,1,2,3$ indicate that the constant parameters should be estimated. Estimate the constant parameters using the method in (1). The 38 observations sets from 1980-2017 for the predictor variables $X_{1}, X_{2}, X_{3}$ and the response variable $Y$ are denoted as $\mathrm{i}=1,2 \cdots 38$. Thus, the sample form of the DLM is

$$
\ln y_{i}=\beta_{0}+\beta_{1} \ln x_{i 1}+\beta_{2} \ln x_{i 2}+\beta_{3} x_{i 3}+\varepsilon_{i}, i=1,2 \cdots 38
$$

And 


$$
X=\left[\begin{array}{ccc}
\ln x_{11} & \ln x_{12} & \ln x_{13} \\
\ln x_{21} & \ln x_{22} & \ln x_{23} \\
\vdots & \vdots & \vdots \\
\ln x_{n 1} & \ln x_{n 2} & \ln x_{n 3}
\end{array}\right] \ln Y=\left[\begin{array}{c}
\ln y_{1} \\
\ln y_{2} \\
\vdots \\
\ln y_{n}
\end{array}\right], \hat{\beta}(k)=\left(\begin{array}{c}
\hat{\beta}_{1}^{\prime} \\
\hat{\beta}_{2}^{\prime} \\
\hat{\beta}_{3}^{\prime}
\end{array}\right) n=38
$$

Based on the ENE, the parameter estimation procedure of equation (3) is as follows.

- The observations sets are divided into 5 copies, which are random and non-repetitive.

- 1 copy is the test set and the remaining 4 copies are used as the sets for training the model each time.

- Repeat ii 5 times. Hence, each subset is given one chance to be used as a test set. After training on each training set to obtain a model, test this model on the corresponding test set and calculate the evaluation metrics of the model.

- Test this model on the corresponding test set, calculate and save the evaluation metrics of the model.

- Calculate the average of the 5 sets of test results as an estimate of the model accuracy.

The results show that the model obtains the optimal solution when the parameter $\alpha=0.1, \lambda=0.00028$. At this time, the constant parameter values $\beta_{0}=4.423, \beta_{1}=0.027, \beta_{2}=-0.092, \beta_{3}=0.56$. The following regression equation is obtained

$$
\ln \vec{Y}=4.423+0.027 \ln X_{1}-0.092 \ln X_{2}+0.56 \ln X_{3}
$$

That is

$$
\vec{y}_{i}=e^{4.423} x_{i 1}{ }^{0.027} x_{i 2}{ }^{-0.092} x_{i 3}{ }^{0.56}
$$

It is concluded from equation (4) that the number of new students enrollment by regular institutions of higher education, number of hospital beds, length of railways in operation increased by $1 \%$, the total population of Heilongiiang Province increased by $0.027 \%,-0.092 \%$, and $0.56 \%$. The results of the DLM show that the increase of the number of new students enrollment by regular institutions of higher education and length of railways in operation has led to the promotion of total population growth in Heilongjiang Province. The increase in the number of beds has not contributed to an obvious increase in the total population of Heilongjiang Province.

The trends of fitted and true values of the total population in Heilongjiang province are shown in Figure 1, the predicted values and relative error are shown in Table 1, and the trends of the natural growth rate in Heilongjiang from 2010-2019 are shown in Figure 2.

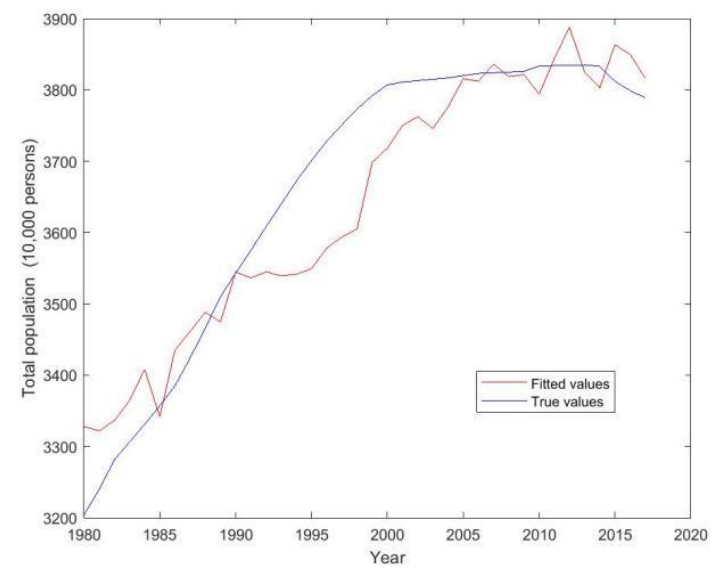

Figure 1. Trend of total population in Heilongjiang 


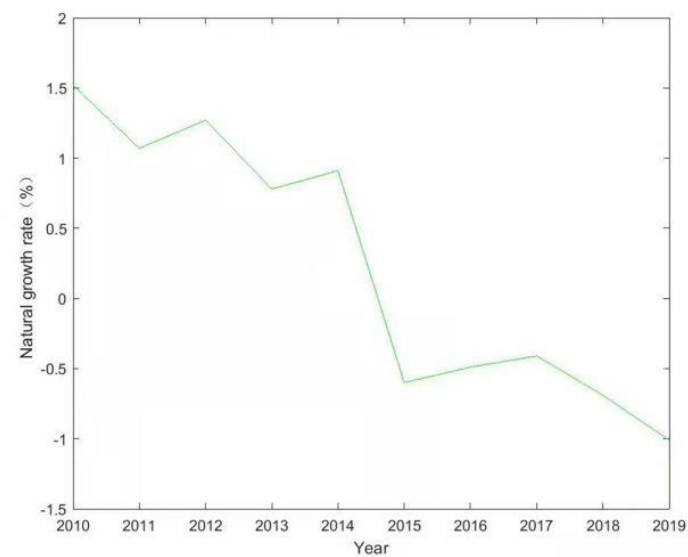

Figure 2. Trend in natural growth rate in Heilongjiang Province

Table 1. Relative error in predicted values of the DLM based on ENE

\begin{tabular}{cccc}
\hline \multirow{2}{*}{ Year } & $\begin{array}{c}\text { True values } \\
(10000 \\
\text { persons })\end{array}$ & $\begin{array}{c}\text { Predicted values } \\
(10000 \text { persons })\end{array}$ & $\begin{array}{c}\text { Relative error } \\
(\%)\end{array}$ \\
\hline 2018 & 3773.1 & 4037.8 & 7.02 \\
2019 & 3751.3 & 4008.9 & 6.87 \\
\hline
\end{tabular}

\section{Discussion of the Model}

\subsection{Comparison of Model}

The proportion of tertiary education and population (\%) reflects the level of educational development in Gansu Province. The results show that the level of education in the region influences population migration (Tang, 2016). There is a mutually constraining and influential relationship between the various elements of population migration and economic development in China's northeastern region (Yu, 2017). The $\mathrm{GM}(1,1)$ model was used to predict population size in Heilongjiang Province through statistics from 1997-2011 (Jiang, 2013). Based on Song Jian discrete population evolution equation, the mortality function and fertility function of Heilongiiang Province are also solved numerically (Wang, Wang, Jiang \& Xuan, 2014). A combined GM(1,1)-SVM model improves the prediction accuracy of population size (Xu \& Hou, 2020). Forecasts of China's population size based on the Logistic Model, the GM(1, 1) Model, and the Linear Model conclude that all three models can describe China's population change (Yang, 2017). This paper compares the DLM based on ENE and the GM(1,1) model using population data of Heilongjiang province from 1980-2017 (Table 2). The results show that the average relative error of the fitted value of the DLM based on ENE is 1.62, and that of the $\operatorname{GM}(1,1)$ model is 2.08. Therefore, the DLM based on ENE has a better fitting effect on the population size of Heilongjiang Province compared with the $\operatorname{GM}(1,1)$ model. In addition, none of the above papers quantitatively analyzed the impact of social-economic factors on population change in Heilongjiang Province. The paper adds to this research. 
Table 2. Fitting values of the DLM compared with the GM $(1,1)$ model regarding the population size of Heilongjiang Province

\begin{tabular}{|c|c|c|c|c|c|}
\hline Time & True value & $\begin{array}{c}\text { Fitted value for the } \\
\text { GM }(1,1) \text { model }\end{array}$ & $\begin{array}{c}\text { Relative error } \\
(\%)\end{array}$ & $\begin{array}{c}\text { Fitted value of } \\
\text { DLM }\end{array}$ & $\begin{array}{c}\text { Relative error } \\
(\%)\end{array}$ \\
\hline 1980 & 3203.8 & 3203.8 & 0.00 & 3328.0 & 3.88 \\
\hline 1981 & 3239.3 & 3395.6 & 4.83 & 3321.8 & 2.55 \\
\hline 1982 & 3281.1 & 3410.1 & 3.93 & 3336.1 & 1.68 \\
\hline 1983 & 3306.0 & 3424.8 & 3.59 & 3364.1 & 1.76 \\
\hline 1984 & 3331.0 & 3439.5 & 3.26 & 3408.1 & 2.31 \\
\hline 1985 & 3357.0 & 3454.2 & 2.90 & 3341.8 & 0.45 \\
\hline 1986 & 3385.0 & 3469.0 & 2.48 & 3435.0 & 1.48 \\
\hline 1987 & 3424.0 & 3483.9 & 1.75 & 3461.2 & 1.09 \\
\hline 1988 & 3466.0 & 3498.8 & 0.95 & 3488.2 & 0.64 \\
\hline 1989 & 3510.0 & 3513.9 & 0.11 & 3474.6 & 1.01 \\
\hline 1990 & 3543.0 & 3528.9 & 0.40 & 3544.6 & 0.05 \\
\hline 1991 & 3575.0 & 3544.1 & 0.86 & 3536.3 & 1.08 \\
\hline 1992 & 3608.0 & 3559.3 & 1.35 & 3544.9 & 1.75 \\
\hline 1993 & 3640.0 & 3574.5 & 1.80 & 3539.3 & 2.77 \\
\hline 1994 & 3672.0 & 3589.8 & 2.24 & 3541.4 & 3.56 \\
\hline 1995 & 3701.0 & 3605.2 & 2.59 & 3549.2 & 4.10 \\
\hline 1996 & 3728.0 & 3620.7 & 2.88 & 3578.1 & 4.02 \\
\hline 1997 & 3751.0 & 3636.2 & 3.06 & 3593.7 & 4.19 \\
\hline 1998 & 3773.0 & 3651.8 & 3.21 & 3605.0 & 4.45 \\
\hline 1999 & 3792.0 & 3667.5 & 3.28 & 3698.5 & 2.47 \\
\hline 2000 & 3807.0 & 3683.2 & 3.25 & 3718.4 & 2.33 \\
\hline 2001 & 3811.0 & 3699.0 & 2.94 & 3750.1 & 1.60 \\
\hline 2002 & 3813.0 & 3714.9 & 2.57 & 3762.4 & 1.33 \\
\hline 2003 & 3815.0 & 3730.8 & 2.21 & 3745.9 & 1.81 \\
\hline 2004 & 3816.8 & 3746.8 & 1.83 & 3776.1 & 1.07 \\
\hline 2005 & 3820.0 & 3762.9 & 1.49 & 3815.7 & 0.11 \\
\hline 2006 & 3823.0 & 3779.0 & 1.15 & 3812.1 & 0.29 \\
\hline 2007 & 3824.0 & 3795.2 & 0.75 & 3836.0 & 0.31 \\
\hline 2008 & 3825.0 & 3811.5 & 0.35 & 3818.7 & 0.16 \\
\hline 2009 & 3826.0 & 3827.9 & 0.05 & 3821.4 & 0.12 \\
\hline 2010 & 3833.4 & 3844.3 & 0.28 & 3794.1 & 1.03 \\
\hline 2011 & 3834.0 & 3860.8 & 0.70 & 3843.5 & 0.25 \\
\hline 2012 & 3834.0 & 3877.3 & 1.13 & 3888.0 & 1.41 \\
\hline 2013 & 3835.0 & 3893.9 & 1.54 & 3824.7 & 0.27 \\
\hline 2014 & 3833.0 & 3910.6 & 2.02 & 3802.9 & 0.79 \\
\hline 2015 & 3812.0 & 3927.4 & 3.03 & 3863.4 & 1.35 \\
\hline 2016 & 3799.2 & 3944.3 & 3.82 & 3849.7 & 1.33 \\
\hline 2017 & 3788.7 & 3961.2 & 4.55 & 3816.0 & 0.72 \\
\hline
\end{tabular}

\subsection{Analysis and Recommendations}

Mean square error of DLM based on ENE is 0.018 and $\mathrm{R}^{2}$ is 0.919 . The value of $\mathrm{R}^{2}$ is close to 1 , indicating that model (4) is a good fit for the observed values.

Looking at Figure 1, the blue curve representing the true value of population size in Heilongjiang has a consistent overall trend with the red curve representing the fitted value of the DLM based on the ENE. The blue curve has intersection points with the red curve in Figure 1, indicating that model (4) has a good fit and can describe the trend of population change in Heilongjiang Province.

Comparing the true and fitted values of population size in Heilongjiang Province shows that for 1980-1990 and 2010-2017, the red line representing the fitted values is mostly above the blue line representing the true values. Therefore the fitted values are considered to be greater than the true values. 1990-2010, the red line representing the fitted values is mostly below the blue line representing the true values and the true values are considered to be greater than the fitted values. Thus between 1980 and 1990, social-economic factors contributed to the growth of population numbers in Heilongjiang Province. The contribution of social-economic factors to population numbers in Heilongjiang 
Province diminished between 1990 and 2010 compared to 1980-1990.

From 1953-1980, the Heilongjiang Province had a net inflow of 5,968,500 people. 2000 data and 2010 data show a net outflow of 787,000 and 2,047,000 people from Heilongjiang Province, respectively (Li, 2015). Before the Reform and Opening (1978), Heilongjiang Province was one of the fastest- growing cities in China in terms of population. However, data from the 1990 census shows that the population of Heilongjiang grew at a slower rate, while from 2000-2010, Heilongjiang province experienced an average net out-migration of about 70,000 people per year (Hou, 2010). Heilongjiang Province is one of the original old industrial areas in China. It used to be a popular area for economic growth and needed labor before the Reform and Opening. After the 1990s, the number of people on the move in China increased. China prioritizes building its eastern coastal regions. As a result, the ability of China's developed eastern coastal areas to attract mobile populations has increased significantly, and the power of Heilongjiang Province to attract migratory populations has decreased substantially. The conclusions of this paper are consistent with the trends in population change in Heilongjiang Province.

Heilongjiang's family planning policy has been effective, with a natural population growth rate of less than $20 \%$ from 1978 to the mid-20th century, and less than $10 \%$ from 2000 to 2010 (Hou, 2010). From 2010-2017, social-economic factors had a positive effect on promoting the growth of population numbers in Heilongjiang Province, and considering that both natural and social-economic factors have an impact on the change of regional population numbers, the population numbers in Heilongjiang Province were influenced to a certain extent by natural factors such as the natural growth rate during this period. Figure 2 shows that the natural population growth rate has continuously decreased in Heilongjiang Province from 2010-2019. During 2015-2019, the natural population growth rate in Heilongjiang province has been negative for five consecutive years.

The above analysis shows that to promote the stable growth of population in Heilongjiang province, the government should consider two aspects: firstly, the government should take measures to enhance people's willingness to have children and increase the natural population growth rate. Secondly, the government should promote the economic prosperity of Heilongjiang province to reduce the outflow of population from Heilongjiang province and attract people from other cities to settle in Heilongjiang to achieve a virtuous cycle of development of the population and comprehensive strength of Heilongjiang.

\section{Conclusion}

This paper has developed a double-logarithmic model based on elastic net estimation to analyze the impact of social-economic factors on the population size of Heilongjiang Province. The development of education and transportation conditions have contributed to the enhancement of the population of Heilongjiang Province. Still, the advancement of health conditions has not contributed to the growth of the population size of Heilongjiang Province. The limitation of this paper is that, due to the limitation of the data collected, it only studies the impact of social-economic factors such as education, health care and transportation on the change in population numbers in Heilongjiang Province after the reform and opening up, and does not quantitatively analyze the impact of social-economic factors on the change in population in Heilongjiang Province before the reform and opening up. The impact of social-economic factors on the size of the population in Jilin and Liaoning provinces and on the size of the population in Northeast China could be the next research topic. It would also be valuable to further analyse the impact of social-economic factors on the change in population size in China by comparing the impact of social-economic factors on the change in population size in the western region, coastal cities and the northeastern region.

\section{References}

Chi, M. (2015). Economic analysis of China's adjustment of her population policy(dissertation for doctoral degree ). Jilin University, Jilin, China.

Cruz, M., \& Ahmed, S. A., (2018). On the impact of demographic change on economic growth and poverty. World Development, 105, 95-106. https://doi.org/10.1016/j.worlddev.2017.12.018

Ding, J. (2021). Infectious Diseases and their Impact on North American Population before Mid-Nineteenth Century. Journal of Sichuan University ( Philosophy and Social Science Edition)

Du, J. (2013). The impact of population migration on economic and social development in Heilongjiang Province. Jilin University, Jilin, China. https://doi.org/CNKI:CDMD:1.1013.187822

Guo, J. (2014). Analysis on population distribution and influencing factors in Sichuan. Sichuan Normal University, Sichuan, China.

Hou, J. (2010). The impact of the low fertility rate on the future's population development of northeast China(dissertation for doctoral degree). Jilin University, Jilin, China. 
https://doi.org/CNKI:CDMD:1.2010.107497

Jiang, S. (2013). Study on the prediction of population quantity and structure of Heilongjiang province. Harbin Institute of Technology, Harbin, China.

Kline, J. D., Montgomery, C. A., \& Lee, Y. (2016). The influence of age-specific migration on housing growth in the $\begin{array}{llllll}\text { rural midwest (USA). Landscape \& Urban Planning, } & 148, & 68-79 .\end{array}$ https://doi.org/10.1016/j.landurbplan.2015.12.005

Li, G., \& Chen, X. (2009). Empirical research on influencing factors on population growth of Beijing-Tianjin-Hebei Metropolitan Region. Geological Research, 28(01), 191-202. https://doi.org/10.3321/j.issn:1000-0585.2009.01.020

Li, P. (2015). Study on the influence of migration of population in Heilongjiang Province on regional economic development. Jilin University, Jilin, China. https://doi.org/CNKI:CDMD:2.1015.595901

Li, P., Tian, L., \& Huang, W. (2021). Improvement and empirical test of population migration gravity model based on system dynamics. Systems Engineering-Theory \& Practice, 41(07), 1722-1731.

Markov, N. I. (1997). Population dynamics of wild boar, Sus scrofa, in Sverdlovsk oblast and its relation to climatic factors. Russian Journal of Ecology, 28(04), 269-274.

Pang, J. (2007). Study on the economic and social impacts of population migration and countermeasures in Qingdao city(dissertation for doctoral degree). Qingdao University, Qingdao, China. https://doi.org/10.7666/d.y1096867

Shen, W., \& Wu, X. (2013). Research on factors influencing Beijing population growth based on data mining. China Population, Resources and Environment, 23(S2), 470-473. https://doi.org/cnki:sun:zgrz.0.2013-s2-118

Tang, J. (2016). The research of population distribution pattern of space and time in Gansu province and its influencing factors. Central China Normal University, Wuhan, China.

Wang, G., \& Huang, Z. (2014). The growth composition of urban population in China and its contribution to urbanisation:1991-2010. Chinese Journal of Population Science, (02), 2-16+126.

Wang, L., Feng, Z., \& Yang, Y. (2015). The change of population density and its influencing factors from 2000 to 2010 in China on county scale. Acta Geographica Sinica, 69(4), 1790-1798. https://doi.org/10.1007/s11442-015-1181-z

Wang, Y. (2015). The study of population trends in rural China-based on the discussion of estimating methods of fertility level and migration(dissertation for doctoral degree ). Nanjing Agricultural University, Nanjing, China.

Wang, Y., \& Zhao, X. (2020). The micro-factors and their changes that affect the social integration of the migrant population: based on the comparison between 2010 and 2017. Journal of East China Normal University (Humanities and Social Sciences). https://doi.org/10.16382/j.cnki.1000-5579.2020.01.012

Wang, Y., Wang, F., Jiang, D., \& Xuan, Y. (2014). A Model Based on Song Jian Discrete Population evolution equations applied in Population Forecast and Analysis of Heilongiiang Province. Mathematics in Practice and Theory, (10), 5. https://doi.org/CNKI:SUN:SSJS.0.2014-10-027

Willi, Y., Hoffmann, A. A., (2009). Demographic factors and genetic variation influence population persistence under environmental change. Journal of Evolutionary Biology, 22(1), 124-133. https://doi.org/10.1111/j.1420-9101.2008.01631.x

Xu, X., \& Hou, R. (2020). Medium and long-term population prediction based on GM(1,1)-SVM combination model. Computer Science, 47(S01), 4.

Yan, D., Sun, W., Wang, Y., \& Xu, S. (2020). Change in distribution and growth shifts of population in the Yangtze River Delta and influencing factors. Progress In Geography, 39(12), 2068-2082. https://doi.org/10.18306/dlkxjz.2020.12.009

Yang, C. (2016). Population agglomeration and dynamics mechanisms of China's multi-scale urbanization -from the perspective of population mobility. East China Normal University, Shanghai, China.

Yang, Y. (2017). Prediction of China's total population based on the universal two-child policy. University of Science and Technology of China, Hefei, China

Yin, X., Li, P., Feng, Z. M., You, Z., Xiao, C. W. (2021). Characteristics of spatio-temporal differences and evolution types of Vietnamese population from 2000 to 2019. World Regional Studies.

$\mathrm{Yu}$, T. (2017). The Study on relationship between population migration and regional economic development in the Northeast China(dissertation for doctoral degree ). Northeast Normal University, Changchun, China. https://doi.org/CNKI:CDMD:1.1018.006602 
Zhang, L. (2019). Study on the outflow of population and its effects in Heilongjiang Province. Jilin University, Jilin, China.

Zheng, W. (2007). Analysis of factors affecting population growth in mid-western cities. Population Research. (04), 77-79. https://doi.org/10.3969/j.issn.1000-6087.2007.04.011

Zhong, S. (2020). The Study of the factors that influence the growth of the urban population in China. Journal of capita University of Economics and Business, 15(02), 22-29. https://doi.org/10.3969/j.issn.1008-2700.2013.02.003

Zhou, H. (2018). The impact of demographic transformation on Chinese economic growth-based on the perspective of population quantity and population quality(dissertation for doctoral degree ). Shandong University, Shandong, China.

Zhu, Q. (2013). Research on the change of the family planning policy since the founding of the PRC(dissertation for doctoral degree ). Hunan Normal University, Hunan, China.

\section{Copyrights}

Copyright for this article is retained by the author(s), with first publication rights granted to the journal.

This is an open-access article distributed under the terms and conditions of the Creative Commons Attribution license (http://creativecommons.org/licenses/by/4.0/). 